\title{
The Limits to Our Capacity: Reflections on Resiliency, Community Engagement, and Recovery in 21st-Century Crises
}

Frederick M. Burkle Jr, MD, MPH, DTM

"Disasters keep governments honest by defining the public health and exposing its vulnerabilities."

F.M. Burkle Jr, 1973

$\mathrm{D}$ isaster resiliency, as it relates to postdisaster community recovery, is a slippery term that can be misunderstood, if not outright abused. It is difficult to find a universal definition of resiliency that satisfies all of the disciplines that claim ownership of the term and satisfies the 1-definition rule that would measure its impact on individuals, communities, and society. It has been labeled everything from a metaphor to a theory, ${ }^{1}$ and some authors, although they include acts of nature such as hurricanes, floods, and earthquakes in their studies of resiliency, exclude mass violence such as wars and terrorism, epidemics, and pandemics. The world is more complicated as are the ways in which society abuses it. Clearly, there are limits to that resiliency, especially in extreme humangenerated disasters, ready examples being unconventional warfare and terrorism, bioterrorism agents that defy both investigation and control, and major nuclear war for which few possess innate resiliency, physical and emotional, to survive.

Disasters have the uncanny ability to immediately reveal and define the status of public health protections and expose community vulnerabilities. ${ }^{2}$ We must address questions such as why, during Hurricane Katrina, did Mississippi, which took a harder hit than New Orleans, recover quickly, more smoothly, and without fanfare $?^{3}$ We still ignore the fact that the hurricane, although a natural event, also was a preventable humangenerated disaster produced by previously known and welldocumented failure of the levees that society believed would protect them. Skill and competence of a government, or lack thereof, can have profound effects on vulnerability and whatever resilience can be mustered to cope at the final hour, a process called managed resiliency. ${ }^{4}$ Recent crises have convinced many sectors of society that there is a limit to that capacity and new measures are necessary. By using the background of what we know and do not know about modern-day disaster experiences, communities must answer questions such as the following:

- How can we respond to disasters and other human crises with dignity and act in accordance with the lived experience of others?

- In community participation and governance, who is listening?

- What prevention, preparedness, and response modalities will benefit communities in mitigating the limits to resiliency and fostering sustainability?
To help answer these questions and others that arise, it is crucial that we drill deeper into understanding the nuances of crises that affect how vulnerability and resiliency plays itself out at the community level.

\section{LESSONS FROM 9/11}

In many ways, resilience has been tested on the North American psyche more by the terrorist events of September 11,2001 (9/11) than by any other event. Bonanno and colleagues in 2006, using a 17-symptom survey that constitutes posttraumatic stress disorder (PTSD), analyzed 2800 broad New York populations 6 months after the terror attacks. ${ }^{5}$ Participants were asked how close they had been to the attacks, whether they had been physically injured by them, and whether they had lost loved ones in them. They concluded that "resilience" (defined as 1 or no PTSD symptoms) was observed in $65 \%$ of the sample. The "frequency of resilience never fell below one third of the respondents even among the exposure groups with the most dramatic elevations in PTSD" (those who experienced both death of a loved one and witnessed the attack). ${ }^{5}$ Critics of this study, although recognizing the "need to take resilience seriously as a subject of scientific investigation," believed that "future studies have to be designed to capture and understand resilience as an outcome and process that is much more than the absence of psychopathology." Marshall and colleagues cautioned that although "only 65 percent of persons did not experience any symptoms of illness ... resilience should have been in the 90th percentile," further emphasizing the need to devote "much more attention to ways to enhance resilience and promote recovery." In 2007, they attempted to explain why large numbers of people had postraumatic symptoms post-9/11 but did not fit the traditional definition of "exposure." They defined the term relative risk appraisal to "capture the psychological function that is the missing link between the event and subjective response" in 9/11- and other terrorism-related studies. The study suggests that human perception is an "active multidimensional process in which proximity to the event is only one of several factors" giving credence to explain the wider societal vulnerability that was seen. ${ }^{7}$

Furthermore, Kilcullen asserted that "It is not the people al-Qaeda might kill that is the threat... Our reaction is what can cause the damage. It's al-Qaeda plus our response that creates the existential danger." ${ }^{8}$ Resilience can be mea- 
sured by capacity to recover and maintain function, but additional stress on the psyche comes from impending, noncontemporary fear. In the post-9/11 time frame it is important to determine what it is that we fear most, what new decisions are made (eg, travel by train vs plane), what indicates the presence and hold of fear on the quality of life performance, and whether the delayed indirect consequences of fear risk taking a greater psychosocial and behavioral toll than that caused by any overt act of terrorism? A RAND study found that adults in the United States reported "accomplishing less work (65\%), avoiding public gatherings (24\%) and using alcohol to relax, sleep better or feel better (38\%)." Whereas $75 \%$ talked with family and friends, $43 \%$ reported being unable to share their terrorism-related thoughts and feelings because it made others feel uncomfortable. ${ }^{9}$

\section{LARGE-SCALE WEATHER-RELATED DISASTERS}

In May 2011, United Nations Secretary General Ban Kimoon acknowledged that "as a result of global climate change, weather-related hazards are on the rise," reasserting that the "destruction wrought by such events can be avoided or mitigated by enhancing resilience through technology and other measures aimed at boosting preparedness." ${ }^{10}$ The 1991 Bangladesh cyclone, one of the deadliest tropical cyclones ever recorded, killed more than 138000 people and left tens of millions homeless, yet survivors quickly gathered up corrugated metal sheeting and other remnants of their former homes to reconstruct their lives. Societies that occupy disaster-prone areas incorporate resilience into their cultures, a trait often lacking in more "fortunate" parts of the world. ${ }^{11}$ The same survivors are gradually being driven out of their historical home sites by rising oceans that claim low-lying shoreland and surrounding islands and find themselves externally and internally displaced in unfamiliar and security-poor urban slums facing unprecedented daily challenges to survival.

In the United States, Hurricane Katrina emerged as a major laboratory, welcomed or not, for the study of vulnerability and resiliency. Eight major findings on resilience have been gleaned from the history of New Orleans. ${ }^{4,12,13}$ Authors acknowledge the history of multihazards, including 27 major floods in 290 years, yellow fever epidemics, 20th-century drinking water pollution, and a declining population-based economy that was further decimated and accelerated by Hurricane Katrina. Five years after the disaster, only $70 \%$ of the population has returned to New Orleans, only $30 \%$ of building permits for residences have been issued, and the leading economic sectors such as health care and undergraduate and graduate education are still recovering. ${ }^{14}$

Resilience for New Orleans in past years depended primarily on shaky short-term flood protection rather than a strategy of enhancing a more robust levee and water drainage system. ${ }^{4}$ In many ways their fragile luck ran out. Too many surprises emerged from a series of "unanticipated events, correctly anticipated events but failed responses, and wrongly anticipated events." The best scientific and technological knowledge did not get used or widely disseminated. For example, engineering designs written for improved protective structures that took into account the effects of storm surge, out-of-sight shrinkage and settling of the land brought on by accelerated extraction of groundwater and rising sea levels measured at that time were ignored for decades. Unwisely, outdated estimates were still being used 19 years later, when sea levels had risen and land had lowered much more ( $\geq 10 \mathrm{ft}$ ) than expected. To compound the problem, the widely used Federal Emergency Management Agency risk assessment maps of the 100-year floodplain were never included in the new data. ${ }^{4}$

Partnerships essential to community-based resilience that usually "emerge from households, friends, family, neighborhoods, non-governmental and voluntary organizations, businesses, and industry" were repeatedly ignored. When the disaster struck, these "shadow responders" who provided "most of the initial evacuation capacity, sheltering, feeding, health care and rebuilding much of the search and rescue, cleanup, and post-Katrina funding" were "refused or poorly used by government officials." The political and governance system in New Orleans was arguably inept; in contrast, neighboring Mississippi's good governance, effective community-level partnerships, and preparedness defined how best practices in resiliency and recovery were experienced. ${ }^{4}$

A postdisaster study in 2006 confirmed that New Orleans had experienced a $47 \%$ increase in deaths over the prehurricane baseline. ${ }^{15}$ Evidence came from nontraditional community source: the Times-Picayune newspaper, prompted by citizens, who had alerted the newspaper of a seemingly inordinate, incorrect number of published obituaries. The antiquated and hurricanedisabled Department of Public Health information system that monitored surveillance data in New Orleans was no longer functioning and personnel were unaware of the mounting indirect deaths that arose from compromised public health protections and services such as mental health. ${ }^{15}$

\section{H1N1 AND GLOBAL RESILIENCY}

Many major crises will only be solved once the community of nations recognizes that they have a global responsibility beyond their own borders. During the 2003 severe acute respiratory syndrome (more commonly known as SARS) pandemic, the United Nation's Assembly of Health Ministers had to act immediately to avert a worldwide catastrophe by granting the World Health Organization (WHO) unprecedented emergency powers to assist actively in the investigation and to take control in all countries that reported outbreaks of the virus. These formal actions, which were instrumental in limiting the further spread of SARS, became the basis of the permanent International Health Regulation (IHR) treaty in 2007 and a pivotal model for operational resiliency at the global level. ${ }^{16}$ The treaty requires compli- 
ance from countries to provide real-time surveillance of emerging and reemerging communicable diseases, and provides the WHO authority with additional emergency response teams ready to deploy to countries where these resources are lacking. Despite initial skepticism and bureaucratic resistance, the treaty process of global cooperation works. These global capacities provided less-advantaged countries with construction and monitoring of their surveillance and response capabilities to contain the highly lethal avian influenza and the 2009 H1N1 epidemic from spreading. Confidence and resiliency has increased greatly in countries that understand the protective aspects of the IHR treaty and WHO's authority within the global community. ${ }^{17,18}$

Were it not for the IHR treaty, the course of the H1N1 pandemic would have been more chaotic and widespread. Viral seed strains and control reagents were ready in a few weeks, the firstcandidate vaccine was available within 32 days of the declaration of the international public health emergency, and efficient distribution of more than 3 million treatment courses of antiviral drugs to 72 countries was accomplished. The H1N1 pandemic also revealed that in future declarations of a public health emergency of international concern it may not be possible to determine early on the severity of the outbreak or have a viable vaccine available before 6 months. ${ }^{17}$ This confirmed the critical priority that strong public health situational awareness and mitigation strategies have in diminishing adverse community-level outcomes. For those who recognize that future generations will live in a world of greater global awareness, especially in public health, the success of the IHR treaty suggests that a similar authoritative model would better serve large-scale natural disasters.

\section{NUCLEAR RISK AND RESILIENCY}

The nuclear power industry is in a state of global decline, a situation that is not going to change in the foreseeable future. ${ }^{19}$ The tragedy in Sendai, Japan has awakened unsettling yet lingering fear, especially among populations living with nuclear reactors in locations that are considered disaster prone. The greatest threats come from earthquakes, tsunamis, fires, flooding, tornadoes, or terrorist attacks. In Nature, Butler reports that at least two-thirds of the world's 211 nuclear plants have more than 1 million people living within $75 \mathrm{~km} .{ }^{20}$ Population numbers and densities are only 1 factor. Each reactor, Butler states, has its own "unique risk profile and some risks are simply unknowable." The age of the reactor is not necessarily a major risk ${ }^{20}$ : The Sendai reactor was old and scheduled to be shut down within 1 week, but the Three Mile Island plant was only 3 months old, the Chernobyl reactor only 2 years in operation, and the French Civaux-1 reactor in service less than 5 months. ${ }^{20}$

While we scurry to study and learn more about nuclear reactor risks, most revealing is that reactor safety is dependent ultimately on high-quality maintenance and training, competence of the operator and the workforce, and the rigor of regulatory oversight. ${ }^{20}$ In 2004, the Nuclear Energy Agency cautioned that "employers require more engineers and scientists having a nuclear component to their education than those graduating." ${ }^{21}$ Plant managers are struggling to maintain competence levels. This is happening at a time when one-third of the nuclear industry's workers are eligible to retire, requiring the industry to recruit and hire more 26000 new employees, not counting those to support new plants. ${ }^{22}$

There is pressure on communities and emergency managers to develop without delay new operational skills in mass evacuation care, radiation detection, screening, and management; radiation-specific triage protocols; mass palliative care resources, nuclear risk-specific, population-based psychosocial and behavioral care management skills; mass sheltering and communication assets ${ }^{23}$; and the preparedness phase collection and storage of autologous peripheral blood stem cells for nuclear plant workers. ${ }^{24}$ It is legitimate to ask whether this process will be transparent and inclusive. Unfortunately, historically, the disciplines of medicine and public health have not been included in planning of nuclear reactor design and in the process of nuclear threat negotiations. The unimaginable health consequences that could come out of such scenarios are rarely part of the arguments that guide negotiations to prevent them. ${ }^{25}$

\section{MISTAKES, MYTHS, AND SUCCESSES}

Many common mistakes and myths, made in the name of preparedness, arise from ignorance. Too commonly the growth of resiliency is impeded by fears perpetuated by politicians' misplaced instincts to withhold information and inability to admit to uncertainty, act transparently, issue guidance on diseases and disease protection, and disseminate information to the public as quickly as possible. We now know that with a modicum of education and training large numbers of noncritically injured people can be well managed within a familiar environment, the community, by capable, nonexpert caregivers, yet little is known about these resources. ${ }^{26}$ The majority of individuals (70\% in 1 study) expected to rely on family members; less than half $(48 \%)$ expected to rely on others in their neighborhoods. ${ }^{27}$ Emergency planners fail to recognize the myriad of interlinked networks to which people belong within a community (eg, ethnic, religious, businesses, institutions) and on which people rely for information and meaning in a crisis. ${ }^{28} \mathrm{Commu}$ nities must incorporate constructive cooperation of citizens into emergency plans rather than excluding them because they assume some lack of expertise.

It is curious how society overlooks or ignores elderly people, who, having experience with tragedy, prove to be the best teachers and model examples of resilience and recovery, especially for young people. Citizens are faced with many challenges that require functional resiliency and a clear head. An Israeli study questioned the "division of older people into a vulnerable or inoculated group." Although they demonstrated higher levels of postwar stress symptoms, they showed higher sense of coherence and predicted recovery. ${ }^{29}$ 
Christchurch, New Zealand experienced 2 major earthquakes in 9 months and continues to stress the limits of capacity for resilience. After the second quake, an additional 100 buildings were added to more than 1000 already slated for demolition. Liquefaction threats from the second quake remain, causing a substantial decline in land levels. More than 3000 homes are without water, proper sewage, or power and must rely on "basin baths" and small emergency rainwater tanks. Residential care, repatriation of loved ones, and the location of available bed space remain concerns ( $\mathrm{McColl} \mathrm{G}$, personal communication, June 13-14, 2011). In a February 2011 news poll, 47.8\% of the population either planned to leave, would leave if could but were tied by property or job, or were prepared to walk away from their homes. An additional $15.4 \%$ did not know what to do. ${ }^{30}$ Noticeable from radio comments and supported by community conversations, "resilience is wearing thin," yet people are gathering increasingly to talk and share support, with health resources actively promoting support. With the strain on overworked emergency medical services personnel and an increase in reported staff illness, "outside staff are being brought in to provide respite (McColl G, personal communication, June 13. 14, 2011)."

Given that these issues are shared globally, we can learn from others. An Australian study supports the idea that any successful response to a disaster situation, and the fear that can impede this performance, is related directly to one's familiarity and content-based perception of risk of the threat itself. Paramedics and first responders ranked nuclear and radiological events as the highest factors for fear and unfamiliarity, followed by outbreaks of new and highly infectious diseases and terrorism; all of these manifest unique implications for prevention, preparedness, education, and training. This study confirms that we cannot separate personal and community resiliency or the way in which we perform during times of stress from how well we understand the knowledge base of the threat itself. ${ }^{31}$

Emergency management trends for climate change consequences emphasize strategic- and tactical-level solutions and ignore local- and community-level requirements. ${ }^{30}$ This trend is found on all continents. ${ }^{32,33}$ Australia, which, among developed countries, is already suffering considerably from the consequences of climate change, has introduced several emergency management agendas to improve resilience. They have added "anticipation and assessment" to the disaster cycle (anticipation-assessment-prevention-preparednessResponse-Recovery), requiring all communities to define both their characteristics and needs based on specific disaster risks. This "registration of risks" as a preemergency requirement is a "precursor to mitigation" through formally registering threat identification and targeting risk assessment resources. This process "enhances the implementation of resilience as more than a metaphor but as a meaningful strategy and a formative framework for best practice." ${ }^{34}$ Controllers of national resources and communities work together to mitigate these risks before disaster strikes. Whether cause and effect actually existed, it is encouraging that with this process in place the recent severe flooding in communities in the northeastern part of Australia did not result in a single death.

\section{VIOLATING PROFESSIONAL BOUNDARIES}

The 11th-hour calls for more inter- and multidisciplinary solutions are universal but risk being politically unpopular when potential solutions seemingly violate conventional and often professionally restrictive boundaries. Operationalizing resiliency is an even greater challenge. Rather than shy away from understanding the raw and uncomfortable details of the causes and consequences of these events, it behooves multidisciplinary professionals in disaster medicine and public health preparedness to become engaged through broad professional- and community-level dialogue, decisions, and discourse. ${ }^{35}$ The Institute of Medicine has been candid in that it is "only possible to achieve a resilient community and an integrated, comprehensive, and resilient health system that can respond effectively to a public health emergency through active collaboration, coordination, and shared responsibility among a broad group of public and private stakeholders and the community itself." ${ }^{36}$

Examples of success exist, all of which are variations on the same multidisciplinary theme. Catalyzed by the global cooperation that was witnessed in the outcomes of the IHR treaty, in 2008 the "One World, One Health" initiative was begun to forge equal, all-inclusive collaborations between physicians, osteopaths, veterinarians, dentists, nurses, and other science-, health-, and environment-related disciplines to combat serious health threats in the 21st century. ${ }^{37}$ The concept provides a worldwide strategy for expanding interdisciplinary and multidisciplinary collaborations and communications in all aspects of health care for humans, animals, and the environment; accelerating biomedical research; enhancing the scientific and public health knowledge base; improving medical education and clinical care; and promoting strength in leadership and management to achieve these goals. ${ }^{37}$ The Woodrow Wilson Center for International Scholars, in addressing revitalizing crosscultural community resiliency from a broad social science and behavioral standpoint, advocates for the importance of a civil society voice, the rise of community as a self-organizing entity, the creation of its own physical and political space, the assurance of safety and time, and the galvanizing aspects of leadership that "transcend[s] organizational and political boundaries." ${ }^{38}$

One of the first goals of the Science and Technology Directorate of the Department of Homeland Security is to strengthen security and resiliency by providing "knowledge products and innovative technology solutions" and to "capture and communicate lessons learned to enhance federal, state, local, and pri- 
vate sector responses to future catastrophic events. ${ }^{39}$ The $\mathrm{Na}$ tional Center for Disaster Mental Health Research identifies 5 multidisciplinary interventions to build disaster-resistant communities $^{40}$ :

1. Develop economic resources, reduce resource inequities, and attend to areas of greatest social vulnerability.

2. Engage local people meaningfully in every step of the mitigation process.

3. Foster interorganizational relationships that rapidly mobilize services for disaster survivors.

4. Boost and protect naturally occurring social supports.

5. Plan for the unexpected by exercising flexibility and building trusted sources of information that function in the face of unknowns.

Multidisciplinary actions by disaster medicine and public health preparedness will ensure that resiliency is rehabilitated and enhanced along with essential infrastructure and system recovery. ${ }^{35}$ Human crises, especially those that have the greatest impact on community survival, require a shift from strictly individually focused needs to those of the population as a whole. Resiliency begins in the individual, as it should; however, obligation, beyond self, allows one to appreciate resiliency as essential to community recovery. The sense of community resiliency remains universal and essential to the human species.

Author Affiliation: Dr Burkle, a Woodrow Wilson International Scholar, is Senior Fellow, Harvard Humanitarian Initiative.

Correspondence: Address correspondence and reprint requests to Dr Frederick M. Burkle Jr, Harvard Humanitarian Initiative, Harvard University, 14 Story St, 2nd Floor, Cambridge, MA 02138 (e-mail: fburkle@hsph.harvard.edu).

Received for publication May 24, 2011; accepted July 11, 2011.

This paper was presented initially at the Woodrow Wilson International Center for Scholars Conference on Disaster Resiliency, Washington, DC, April 11-12, 2011, cosponsored by the Fetzer Institute, a private, nonprofit foundation.

Author Disclosures: The author reports no conflicts of interest.

\section{REFERENCES}

1. Norris FH, Stevens SP, Pfefferbaum B, Wyche KF, Pfefferbaum RL. Community resilience as a metaphor, theory, set of capacities, and strategy for disaster readiness. Am J Community Psychol. 2008;41(1-2):127-150.

2. Burkle FM, Rupp G. Hurricane Katrina: disasters keep us honest. Mon Dev. 2005;23(17):5.

3. Brinkley D. The Great Deluge: Hurricane Katrina, New Orleans, and the Mississippi Gulf Coast. New York: Harper Collins; 2006.

4. Revkin AC. Lessons in resilience from New Orleans. http://dotearth.blogs .nytimes.com/2010/08/13/lessons-in-resilience-from-new-orleans/\#more -23975. Published August 13, 2010. Accessed April 30, 2011.

5. Bonanno GA, Galea S, Bucciarelli A, Vlahov D. Psychological resilience after disaster: New York City in the aftermath of the September 11th terrorist attack. Psychol Sci. 2006;17(3):181-186.

6. Arehart-Treichel J. Are $\mathrm{P} \backslash$ post-9/11 resilience data good or troubling news? Clinical and Research News. Psychiatr News. 2005;40:16.

7. Marshall RD, Bryant RA, Amsel L, Suh EJ, Cook JM, Neria Y. The psychology of ongoing threat: relative risk appraisal, the September 11 attacks, and terrorism-related fears. Am Psychol. 2007;62(4):304-316.
8. Fallows J. More "lessons" of 9/11: resilience, not fear. The Atlantic. http: //www.theatlantic.com/politics/archive/2010/09/more-lessons-of -9-11-resilience-not-fear/62786. Published September 10, 2010. Accessed May 7, 2011.

9. Stein BD, Elliott MN, Jaycox LH, et al. A national longitudinal study of the psychological consequences of the September 11, 2001 terrorist attacks: reactions, impairment, and help-seeking. Psychiatry. 2004;67(2): 105-117.

10. UN News Service. As risks from disasters rise, UN chief calls for better preparedness. http://www.un.org/apps/news/printnews.asp?nid=38327. Accessed May 14, 2011.

11. Chowdhury AM, Bhuyia AU, Choudhury AY, Sen R. The Bangladesh cyclone of 1991: why so many people died. Disasters. 1993;17(4):291304.

12. Wilbanks TJ, Romero Lankao P, Bao M, et al. 2007: industry, settlement and society. In: Parry ML, Canziani OF, Palutikof JP, van der Linden PJ, Hanson CE, eds. Climate Change 2007: Impacts, Adaptation and Vulnerability. Contribution of Working Group II to the Fourth Assessment Report of the Intergovernmental Panel on Climate Change. Cambridge, UK: Cambridge University Press; 2007, 357-390.

13. Colten CE, Kates RW, Laska SB. Three years after Katrina: lessons for community resilience. Environ Sci Policy Sustainable Dev. 2008;50:36-47.

14. McConnell J. New Orleans population nearly 30 per cent lower than before Hurricane Katrina. http://www.dailymail.co.uk/news/article-1353602 /New-Orleans-population-nearly-30-cent-lower-Hurricane-Katrina .html. Published February 4, 2011. Accessed April 30, 2011.

15. Stephens KU Sr, Grew D, Chin K, et al. Excess mortality in the aftermath of Hurricane Katrina: a preliminary report. Disaster Med Public Health Prep. 2007;1(1):15-20.

16. Tobin AM. Summary of SARS in Toronto shows public health "inundated" after WHO advisory. http://www.medbroadcast.com/health_news _details.asp?news_id=4187\&news_channel_id. Published June 2, 2004. Accessed April 12, 2006.

17. World Health Organization Review Committee. Report of the Review Committee on the Functioning of the International Health regulations (2005) and on pandemic influenza A (H1N1) 2009. http://www.who.int/ihr /preview_report_review_committee_mar2011_en.pdf. Published March 7, 2011. Accessed April 29, 2011.

18. Wilson K, Brownstein JS, Fidler DP. Strengthening the International Health Regulations: lessons from the H1N1 pandemic. Health Policy Plan. 2010; 25(6):505-509.

19. Schneider M. 2008 world nuclear industry status report: global nuclear power. http://www.thebulletin.org/web-edition/reports/2008-world-nuclear -industry-status-report/2008-world-nuclear-industry-status-rep. Accessed May 14, 2011.

20. Butler D. Reactors, residents and risks. http://www.nature.com/news/2011 /110421/full/472400a.html. Published April 21, 2011. Accessed May 14, 2011.

21. Organization for Economic Cooperation and Development. Nuclear Competence Building (Summary Report) Nuclear Energy Agency No. 5588. http://www.oecd-nea.org/ndd/reports/2004/nea5588-competence.pdf. Published 2004. Accessed May 10, 2011.

22. Schneider M. Nuclear power in 2010: radiant future or barrier to change? Presentation to the Reform-Group Meeting, Salzburg, September 10, 2010. http://www.polsoz.fu-berlin.de/polwiss/forschung/systeme/ffu /veranstaltungen/veranstaltungen_downloads/10_salzburg/schneider .pdf. Accessed: May 12, 2011.

23. Koenig K, Burkle FM Jr. Downwind from the Great Tohoku earthquake: a call to global action. West J Emerg Med. In press.

24. Tanimoto T, Uchida N, Kodama Y, Teshima T, Taniguchi S. Safety of workers at the Fukushima Daiichi nuclear power plant. Lancet. 2011; 377(9776):1489-1490.

25. Dallas C, Burkle FM Jr. Nuclear war in the Middle East: the voice of medicine and public health. Prehosp Disaster Med. In press.

26. Burkle FM Jr. Population-based triage management in response to surgecapacity requirements during a large-scale bioevent disaster. Acad Emerg Med. 2006;13(11):1118-1129. 
27. Citizen Corps Personal preparedness in America: findings from the 2009 Citizen Corps national survey (revised Dec 2009). http://www.citizencorps .gov/ready/2009findings.shtm. Accessed November 10, 2010.

28. Caruana C. Life in the aftermath: a summary of the literature on individual and family functioning following natural disasters. Fam Relationships Q. 2009;13:3-5.

29. Kimhi S, Hantman S, Goroshit M, et al. Elderly people coping with the aftermath of war: resilience versus vulnerability. Am J Geriatr Psychiatry. 2011 Feb 25 [Epub ahead of print].

30. Christchurch earthquake. http://www.stuff.co.nz/the-press/news/christchurch -earthquake-2011/5233155/Thousands-plan-to-leave-Christchurch - poll. Published February 22, 2011. Accessed June 21, 2011.

31. Smith EC, Burkle FM Jr, Archer FL. Fear, familiarity, and the perception of risk: a quantitative analysis of disaster-specific concerns of paramedics. Disaster Med Public Health Prep. 2010;4:1-8.

32. Burkle FM Jr. Do pandemic preparedness planning systems ignore critical community- and local-level operational challenges? Disaster Med Public Health Prep. 2010;4(1):24-29.

33. Coker R, Mounier-Jack S. Pandemic influenza preparedness in the AsiaPacific region. Lancet. 2006;368(9538):886-889.

34. Rogers P. Development of resilient Australia: enhancing the PPRR ap- proach with anticipation, assessment and registration of risks. Aust J Emerg Manag. 2011;26:54-58.

35. James JJ, Benjamin GC, Burkle FM Jr, Gebbie KM, Kelen G, Subbarao I. Disaster medicine and public health preparedness: a discipline for all health professionals. Disaster Med Public Health Prep. 2010;4(2):102107.

36. Stroud C, Altevogt BM, Goldfrank LR. Institute of Medicine's Forum on Medical and Public Health Preparedness for Catastrophic Events: current initiatives. Disaster Med Public Health Prep. 2010;4(2):174-177.

37. One Health Initiative. http://www.onehealthinitiative.com. Accessed May 10, 2011.

38. Community Resilience. A Cross Cultural Study. Revitalizing Community Within and Across Boundaries. Washington, DC: Woodrow Wilson International Center for Scholars/Fetzer Institute; 2009:59-60.

39. Homeland Security. About the Science and Technology Directorate. http: //www.dhs.gov/xabout/structure/editorial_0530.shtm. Accessed May 10, 2011.

40. Hobfoll SE, Watson P, Bell CC, et al. Five essential elements of immediate and mid-term mass trauma intervention: empirical evidence. Psychiatry. 2007;70(4):283-315, discussion 316-369. 